\title{
PENGARUH LEADER MEMBER EXCHANGE (LMX) TERHADAP KINERJA KARYAWAN MELALUI KEPUASAN KERJA PADA PT. BERLIAN JASA TERMINAL INDONESIA
}

\author{
Nuril Fitriana Indana Zulfa \\ Universitas Negeri Surabaya \\ nurilzulfa@mhs.unesa.ac.id
}

\begin{abstract}
This study aims to determine and explain the effect of leader member exchange on employee performance through job satisfaction at PT. Berlian Jasa Terminal Indonesia. This research is a type of causal research with a quantitative approach with a population of 256 permanent employees, and the sampling technique uses probability sampling with a sample of 156 permanent employees. The statistical analysis used in this research is Structural Equation Modeling (SEM) with AMOS 23.0 software. This study indicates that the leader member exchange has a positive and significant effect on job satisfaction because there is a trusting relationship between superiors and subordinates. Job satisfaction has a positive and significant effect on employee performance because it was following company standards. Leader member exchange does not affect employee performance because it structures the performance appraisal. Job satisfaction cannot be an intervening variable between leader member exchange and employee performance due to high workload.
\end{abstract}

Keywords: employee performance; job satisfaction; LMX.

\section{PENDAHULUAN}

Era globalisasi memberikan peluang sekaligus tantangan bagi semua perusahaan. Agar perusahaan dapat bersaing, maka diperlukan adanya efektivitas dan efesiensi serta keunggulan dari perusahaan pesaingnya, dengan begitu perusahaan dapat bertahan dalam dunia usaha (Nurhaidah \& Musa, 2015). Sumber daya manusia merupakan faktor penting dalam menjalankan maju mundurnya organisasi. Setiap organisasi menginginkan dan berusaha untuk mendapatkan sumber daya manusia yang bisa mewujudkan dan mencapai tujuan organisasi tersebut, maka perlu adanya pengembangan kualitas sumber daya manusia karena banyaknya tuntutan dan aspek yang harus dituju (Susanto, 2019).

Kinerja merupakan hasil dari suatu proses atau tingkat keberhasilan seseorang atau keseluruhan selama periode tertentu di dalam melaksanakan tugasnya baik secara kualitas maupun kuantitas (Sari \& Hadijah, 2016). Menurut Pusparini (2018), kinerja karyawan memengaruhi dari setiap individu agar tidak akan terlepas dari adanya beberapa faktor mendukung kinerja karyawan, salah satunya leader member exchange (LMX). Menurut Sari \& Tiarapuspa (2017) LMX merupakan hubungan antara atasan dengan bawahan dalam membentuk suatu tingkat kedekatan yang mampu menunjukkan adanya LMX dalam organisasi. LMX ialah kualitas pertukaran antara hubungan interpersonal bawahan dengan atasannya (Kong et al., 2016)

Pada penelitian yang dilakukan oleh Duyan \& Yıldız (2018) LMX memiliki pengaruh positif signifikan terhadap kinerja karyawan, dengan adanya hal tersebut menunjukkan adanya LMX yang baik akan berdampak meningkatkan kinerja karyawan. Namun berbeda dengan penelitian yang dilakukan oleh Adi et al. (2018), yang mengatakan tidak terdapat pengaruh signifikan LMX terhadap kepuasan kerja disebabkan oleh kurangnya dukungan dari atasan mereka. Eşitti dan Kasap (2019) mengatakan adanya pengaruh signifikan positif antara LMX terhadap kepuasan kerja yang mana dalam penelitian tersebut menunjukkan adanya LMX yang baik akan memengaruhi kepuasan kerja pegawai. Namun, hal tersebut tidak sesuai dengan penelitian Bhatti et al. (2015) yang menjelaskan tidak terdapat hubungan signifikan LMX terhadap kepuasan kerja. Sehingga menunjukkan LMX belum mampu memberi pengaruh terhadap kepuasan kerja. 
Selain LMX faktor pendukung kinerja karyawan yaitu kepuasan kerja. Menurut Mangkunegara (2017), kepuasan kerja yaitu perasaan menyokong ataupun tidak dari diri pegawai berhubungan dari kondisi diri dan pekerjaannya. Apabila pegawai memeroleh kepuasan kerja tinggi, pegawai akan bekerja dengan maksimal. Dalam penelitian yang dilakukan oleh Inuwa (2016) dan Maharani et al. (2013) terdapat pengaruh positif dan signifikan kepuasan kerja terhadap kinerja karyawan, hal itu berarti semakin besar kepuasan kerja yang dirasakan oleh karyawan maka akan tinggi kinerja karyawan yang didapatkan. Namun, berbeda dengan penelitian Iroegbu (2013) variabel kepuasan tidak berpengaruh signifikan terhadap kinerja karyawan.

PT. Berlian Jasa Terminal Indonesia merupakan anak dari PT. Pelabuhan Indonesia III (persero). Fokus utama dari perusahaan PT BJTI yaitu menangani kegiatan B/M petikemas domestik di Terminal Berlian Tanjung Perak Surabaya. Usaha yang bergerak di bidang jasa ini selalu berusaha untuk meningkatkan kualitas dari kinerja karyawan agar mampu bersaing untuk memasuki dunia keorganisasian dengan lebih baik. Kinerja karyawan merupakan bagian penting untuk menentukan besar atau banyaknya hasil dari produksi, dengan pengerjaan tersebut perlu adanya pengawasan dari atasan. Hubungan dari atasan dan bawahan menentukan adanya kepuasan kerja karyawan, dengan tingkat kepuasan kerja yang tinggi akan membangun emosi positif sehingga lebih rajin dan senang bekerja serta akan berpotensi meningkatkan kinerja karyawan.

Fenomena LMX ini terjadi pada karyawan PT Berlian Jasa Terminal Indonesia. Berdasarkan wawancara dengan narasumber, terdapat hubungan kedekatan antara atasan dengan bawahan, karena pada umumnya karyawan ini bekerja secara tim dan seringnya terjadi komunikasi antara atasan dan bawahan tersebut. Terkadang atasan sering membantu jika pekerja mengalami kendala atau kesulitan serta sesama pekerja lain sering memberi masukan saat bekerja. Selain leader member exchange hal yang menarik untuk diteliti yaitu kepuasan kerja, yang mana kepuasan kerja merupakan bagian dari organisasi yang perlu diperhatikan untuk mencapai tujuan organisasi. Menurut hasil wawancara, karyawan merasa puas dengan adanya hubungan kedekatan antara atasan dan bawahan t. Akan tetapi karyawan tidak terlalu nyaman dengan adanya pekerjaan yang dilakukan, dan merasa pekerjaan dan tanggung jawab yang dilakukan cukup berat serta menguras tenaga. Atas dasar hal tersebut serta adanya kesenjangan penelitian terdahulu (research gap), maka perlu dilakukan penelitian untuk mengetahui apakah ada pengaruh dari LMX terhadap kinerja karyawan melalui kepuasan kerja pada PT. Berlian Jasa Terminal Indonesia.

\section{KAJIAN PUSTAKA DAN PENGEMBANGAN HIPOTESIS}

\section{Leader Member Exchange (LMX)}

Hutama \& Goenawan (2016) menyatakan organisasi dapat dilihat menjadi dua kelompok interaksi yang pertama in group hubungan timbal balik, perasaan senasib dan rasa saling percaya yang dirasakan pada atasan dengan bawahannya. Kedua out groub interaksi formal dalam koridor, memperoleh waktu yang lebih sedikit, serta atasan dianggap sebagai pengawas. Menurut Anggreani \& Sutanto (2013) ada tiga indikator pengukuran LMX pertama saling menghormati satu sama lain antar karyawan. Kedua yaitu trust hubungan aspek secara terus menerus bisa berubah, Ketiga obligation peran harus dilaksanakan yang bersifat interaktif. Menurut Wojtczuk-turek (2013) seorang leader akan membangun hubungan timbal balik yang lebih baik dengan membernya yang memiliki sifat atau bakat yang unik. LMX dapat didefinisikan sebagai pertukaran kualitas hubungan interpersonal antara bawahan dengan atasannya .

\section{Kepuasan Kerja}

Handoko (2014) kepuasan kerja yaitu perasaan menyenangkan dan tidak menyenangkan dengan bagaimana karyawan memandang pekerjaan tersebut. Mangkunegara (2017) menyatakan kepuasan kerja adalah tingkat afeksi (kasih sayang) pekerja dengan pekerjaan di mana situasi berkaitan dengan sikap pekerja atas pekerjaannya. Sementara itu, menurut Maharani et al.,( 2013), indikator pengukur dari kepuasan kerja yaitu the work it self pemberian tugas yang menarik. Kedua yaitu Payment System merupakan sejumlah gaji yang diperoleh serta tingkatan didapatkan yang dianggap pantas dan wajar. 
Nuril Fitriana Indana Zulfa. Pengaruh $L M X$ terhadap Kinerja Karyawan melalui Kepuasan Kerja pada PT. Berlian Jasa Terminal Indonesia.

Ketiga, promotional opportunities kemungkinan kemajuan kemampuan pegawai atau kemungkinan mendapatkan posisi, status dan keterampilan yang lebih baik dalam perusahaan. Keempat, attitude of supervisor kemampuan pengawas untuk memberikan arahan teknis dan dukungan perilaku. co-worker sejauh mana rekan kerja pintar secara teknis, tenaga kerja dapat diandalkan, serta memberikan dukungan sosial.

\section{Kinerja Karyawan}

Menurut Mangkunegara (2017), kinerja karyawan yaitu hasil dari kemampuan diperoleh secara kualitas dan kuantitas dalam melaksanakan tugas sesuai dengan tanggung jawab yang telah diberikan. Hasibuan (2017) menyatakan bahwa faktor yang penting untuk pencapaian tujuan perusahaan yaitu peningkatan disiplin kerja dalam melaksanakan kinerja karyawan. Sementara itu, menurut Siswanto (2015) kinerja merupakan kata yang berasal dari job performance yaitu prestasi kerja yang dicapai oleh karyawan dalam melakukan pekerjaan yang diberikan kepadanya.

Menurut Lie \& Siagian (2018) dalam mengukur kinerja karyawan ada lima indikator. Pertama, kualitas dari kinerja dapat diukur dari pandangan karyawan terhadap kualitas pekerjaan yang dihasilkan dari segi kesempurnaan, keterampilan dalam bekerja, serta kemampuan karyawan melaksanakan tugas. Kedua, kuantitas adalah jumlah dari yang dihasilkan dan dinyatakan atau biasa disebut jumlah unit atau total siklus aktivitas yang dihasilakan. Ketiga, ketetapan waktu adalah tingkat di mana aktivitas keseluruhan selesai pada waktu yang ditentukan. Keempat, efektifitas penggunaan dari sumber daya yang meliputi teknologi, uang, tenaga kerja dan bahan baku bertujuan utuk meningkatkan hasil unit dari sumber daya yang ada. Kelima, kemandirian yaitu tingkat karyawan dapat menjalankan fungsi kerja sesuai dengan komitmen yang bisa dipertanggungjawabkan oleh kantor.

\section{Hubungan antar Variabel}

Menurut Anggreani \& Sutanto (2013) LMX berpengaruh positif dan signifikan terhadap kepuasan kerja karyawan pada departemen penjualan. Adanya peningkatkan kualitas hubungan antara atasan menyebabkan kepuasan kerja akan meningkat. Pramastuti \& Widodo (2015) menyatakan jika LMX berpengaruh positif pada kepuasan kerja. Penelitian oleh Liao et al. (2017) menunjukkan bahwa LMX belum mampu berpengaruh kepada kepuasan kerja hal tersebut tidak sesuai dengan penelitian terdahulu, namun pada penelitian yang dilakukan oleh Eşitti \& Kasap (2019), LMX berpengaruh positif pada kepuasan kerja jika dimediasi oleh dynamic capabilities.

H1 : Diduga leader member exchange (LMX) berpengaruh positif terhadap kepuasan kerja pada PT. Berlian Jasa Terminal Indonesia.

Kepuasan kerja merupakan sikap perasaan menyenangkan serta mencintai pekerjaan yang dicerminkan dari moral kerja, prestasi, serta kedisiplinan yang dapat dinikmati di dalam maupun luar pekerjaan (Hasibuan, 2017). Menurut Wibowo (2014) kepuasan karyawan berupa harapan dari tujuan dan kebutuhan karyawan dapat terpenuhi maka dapat meningkatkan kinerja karyawan, begitupun sebaliknya. Wijaya (2018) mengatakan kinerja akan baik jika kepuasan yang dirasakan oleh karyawan meningkat hal tersebut dikarenakan kinerja karyawan dipengaruhi oleh kepuasan kerja hal tersebut penting untuk perusahaan agar dapat mendongkrak kinerja. Penelitian tersebut didukung oleh penelitian (Ali et al., 2013), bahwa kepuasan kerja berpengaruh terhadap kinerja karyawan.

H2 : Diduga kepuasan kerja berpengaruh positif terhadap kinerja karyawan pada PT. Berlian Jasa Terminal Indonesia.

Menurut Taqiuddin et al. (2018) LMX berpengaruh positif dan signifikan terhadap kinerja karyawan, dikarenakan seorang pemimpin bisa melihat potensi bahannya yang sudah sesuai dengan kemampuannya yang mengakibatkan kinerja pada karyawan meningkat. Pada penelitian Shu \& Lazatkhan (2017) LMX berpengaruh terhadap kinerja karyawan, yang berarti hubungan antara atasan dan bawahan saling berkolerasi karena terdapat kualitas hubungan ditandai dengan kepercayaan, loyalitas, dan kotribusi pada pekerjaannya. Menurut Kartika \& Suharnomo (2016), LMX tidak 
berpengaruh langsung terhadap kinerja karyawan, hal tersebut terjadi dikarenakan hubungan atasan dan bawahan dirasa kurang harmonis dikarenakan atasan dinilai kurang baik dalam menyampaikan intruksi saat bertugas.

H3: Diduga leader member exchange (LMX) berpengaruh positif terhadap kinerja karyawan pada PT. Berlian Jasa Terminal Indonesia.

Menurut Pusparini ( 2018 ) apabila kepuasan kerja telah terpenuhi seperti gaji dan memiliki hubungan yang baik dengan atasan maka bawahan akan merasa lebih memiliki tanggung jawab secara otomatis terhadap pekerjaannya sehingga cenderung menjaga kinerjanya. LMX. Menurut Miner (1998) interaksi antara atasan dan bawahan leader member exchange (LMX) yang berkualitas tinggi akan dapat memberikan suatu dampak seperti meningkatnya kepuasan kerja, produktivitas, dan kinerja karyawan.

H4: Diduga leader member exchange (LMX) berpengaruh positif terhadap kinerja karyawan melalui kepuasan kerja pada PT. Berlian Jasa Terminal Indonesia.

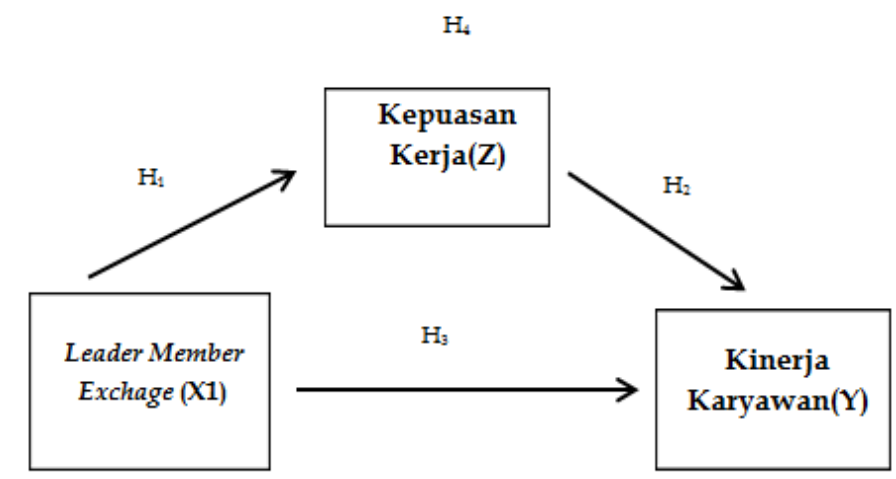

Sumber: data diolah, 2019

GAMBAR 1 KERANGKA KONSEPTUAL

\section{METODE PENELITIAN}

Penelitian ini adalah penelitian kuantitatif yang mana menggunakan data primer dalam melakukan pengambilan data melalui metode wawancara, kuisioner, dan observasi. Dalam penelitian ini menggunakan populasi sebanyak 256 karyawan organik pada PT. Berlian Jasa Terminal Indonesia yang terdiri dari staf dan supervisor. Pada penelitian ini menggunakan rumus Slovin sebagai pengambilan sempel dengan mengunakan tingkat presisi yaitu 5\% $(\mathrm{a}=0.05)$ dalam tingkat kepercayaan yang diterima 95\%, adapun rumus Slovin sebagai berikut:

$n=\frac{\mathrm{N}}{1+\mathrm{Ne}^{2}}$

sumber : Husain (2008)

n : Total anggota sampel

$\mathrm{N}$ : Total populasi

$e^{2} \quad$ : presisi

Hasil dari perhitungan rumus Slovin di atas diperoleh sampel sebesar 156 responden. Pada pengolahan data tersebut penelitian ini menggunakan metode data analisis SEM (Structural Equation Modelling) dan dibantu oleh software analysis of momen structure versi 23. Dalam penelitian ini menggunakan variabel indikator dari Anggreani \& Sutanto (2013) sebagai alat pengukuran LMX, indikator tersebut tiga item diantaranya yaitu trust (kepercayaan), respect (kepedulian), obligation 
Nuril Fitriana Indana Zulfa. Pengaruh $L M X$ terhadap Kinerja Karyawan melalui Kepuasan Kerja pada PT. Berlian Jasa Terminal Indonesia.

(kewajiban). Sedangkan untuk indikator kepuasan kerja merujuk pada indikator Maharani et al. (2013)yaitu the work it self (pekerjaan itu sendiri), payment system (gaji), promotional opportunities (kesempatan promosi), attitude of supervisor (pengawasan), co-worker (rekan kerja). Kemudian untuk indikator kinerja karyawan menggunakan indikator kinerja karyawan menurut Lie \& Siagian (2018) adalah kualitas, kuatitas, pelaksanaan tugas, tanggung jawab, kemandirian.

\section{HASIL DAN PEMBAHASAN}

\section{Karateristik Responden}

Pada penelitian ini jumlah keseluruhan dari sampel tersebut yaitu 156 responden, terdiri dari $127(81,4 \%)$ adalah laki-laki dan $29(18,6 \%)$ perempuan. Karyawan berusia 20-29 tahun berjumlah 42 orang $(22,4 \%)$, karyawan berusia $30-39$ tahun berjumlah 81 orang $(49,4 \%)$, karyawan yang berusia 40 49 tahun berjumlah 26 orang $(23,1 \%)$, karyawan yang berusia $50-59$ tahun berjumlah 7 orang $(5,1 \%)$. Karyawan dengan tingkat pendidikan SLTA sebanyak 32 orang $(18,6)$, yang memiliki tingkat pendidikan D3 berjumlah 17 orang $(12,8)$, untuk tingkat pendidikan S1 adalah 98 orang $(62,8)$, untuk tingkat pendidikan S2 sebabyak 9 orang $(5,8 \%)$. Selanjutnya untuk karyawan yang telah bekerja selama rentang waktu 1-5 tahun berjumlah 62 orang (39\%), untuk yang telah bekerja 6-10 tahun berjumlah 70 orang (44,9\%), selanjutnya yang telah bekerja selama 11-15 berjumlah 20 orang $(12,8 \%)$, karyawan sudah bekerja selama 16-20 tahun yaitu 4 orang $(3,6 \%)$.

\section{Uji Validitas}

Indikator dikatakan validitas ketika nilai loading factor ataupun regression weight $\geq 0,50$ (Ghozali, 2018: 5). Dari hasil analisis semua indikator memiliki nilai standardisize regression weight $\geq 0,50$ dan dinyatakan valid.

\section{Uji Realiabilitas}

Uji reabilitas dikatakan reliabel dilihat menggunakan dua cara, yaitu composite reliability dan cronbach alpha. Menurut Ghozali (2018: 5) suatu alat ukur dinyatakan reliabel jika masing-masing variabel nilainya di atas 0,70 . Dari hasil penelitian masing-masing variabel memiliki nilai di atas 0,70 yang menyatakan bahwa semua pertanyaan dari masing-masing variabel dinyatakan reliabel.

\section{Hasil Koefisien Determinasi}

Ketetapan dari suatu model dapat dilihat pada table Square Multiple Correlation $\left(\mathrm{R}^{2}\right)$ pada analisis untuk nilai dari koefisien determinasi yaitu sebagai berikut:

\begin{tabular}{cc}
\multicolumn{2}{c}{ Tabel 1 } \\
\multicolumn{2}{c}{ HASIL UJI KOEFISIEN DETERMINASI } \\
\hline Variabel & Estimate \\
\hline Kepuasan Kerja & 0,083 \\
Kinerja Karyawan & 0,088 \\
\hline Sumber : $O$ Output AMOS yang diolah, 2020
\end{tabular}

Ketetapan model, didapatkan pada hubungan koefisien determinasi $\left(\mathrm{R}^{2}\right)$ dari kedua persamaan. Dalam perhitungan model dapat dilihat bahwa hubungan ketiga variabel yang diteliti sebesar 0,164 atau $16,4 \%$ untuk sisanya dijelaskan pada variabel lain.

\section{Hasil Uji Analisis Jalur}

Pada model diagram jalur berikut ini dapat dikonversikan ke dalam model hubungan strukural. Berikut ini merupakan hasil analisis jalur yang bisa dilihat pada gambar 2 berikut ini. 


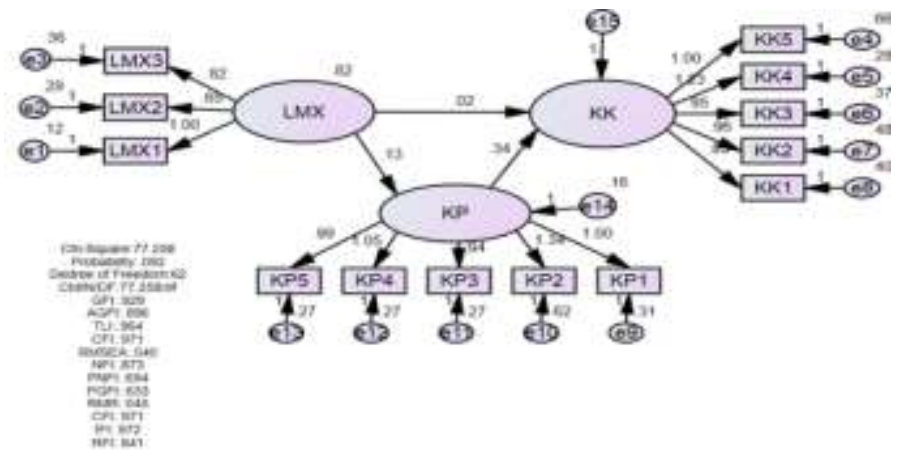

Sumber: output AMOS, 2020

Gambar 2. DIAGRAM JALUR HASIL ANALISIS SEM

\section{Hasil Uji Hipotesis}

Hasil uji hipotesis ini dapat diketahui dari tabel 2. Untuk hipotesis pertama nilai CR hitung lebih besar dari nilai tabel $t$ yaitu sebesar 2,682>1,65. Kemudian nilai probabilitas hipotesis pertama adalah 0,007 $(\mathrm{p} \leq 0,05)$, dengan hal tersebut maka terdapat pengaruh signifikan positif LMX terhadap kepuasan kerja. Hal tersebut menunjukkan hipotesis pertama diterima.

Tabel 2.

HASIL UJI HIPOTESIS

\begin{tabular}{ccccccc}
\hline Hipotesis & Variabel & $\begin{array}{c}\text { Unstandardized } \\
\text { Estimates }\end{array}$ & $\begin{array}{c}\text { Standardized } \\
\text { Estimates }\end{array}$ & S.E. & C.R. & P \\
\hline H1 & $\mathrm{KP} \leftarrow \mathrm{LMX}$ & 0,134 & 0,228 & 0,050 & 2,682 & 0,007 \\
$\mathrm{H} 2$ & $\mathrm{KK} \leftarrow \mathrm{KP}$ & 0,341 & 0,287 & 0,153 & 2,224 & 0,026 \\
$\mathrm{H} 3$ & $\mathrm{KK} \leftarrow \mathrm{LMX}$ & 0,016 & 0,029 & 0,056 & 0,282 & 0,778 \\
\hline
\end{tabular}

Sumber: Data diolah penulis (2020)

Pada hipotesis kedua nilai CR hitung lebih besar dari pada $t$ tabel 2,224>1,65, sedangkan untuk nilai signifikasi probabilitas yaitu $0,0026(\mathrm{p} \leq 0,05)$. Dari hasil tersebut menunjukkan bahwa variabel kepuasan kerja memiliki pengaruh terhadap kinerja karyawan, artinya hipotesis kedua diterima. Pada hipotesis ketiga pada nilai CR hitung lebih kecil dari pada $t$ tabel yaitu sebesar $0,282<1,65$ dan nilai signifikasi probabilitas sebesar $0,778(\mathrm{p} \geq 0,05)$. Hal tersebut menandakan bahwa, variabel LMX tidak memiliki pengaruh terhadap variabel kinerja. Jadi hipotesis 3 ditolak.

\section{Hasil Uji Sobel Test}

\section{Tabel 3}

\section{SOBEL TEST}

\begin{tabular}{cccc}
\hline Variabel & Test Statistic & Std. Error & p-value \\
& & & \\
\hline$L M X$ & 1,71361731 & 0,02666523 & 0,08659903
\end{tabular}

\section{Sumber : Sobel Test, 2020}

Dari hasil uji sobel test pada tabel 3, dapat diketahui nilai signifikansi $0,08659903(\mathrm{p} \geq 0,05)$. Hal tersebut menunjukkan bahwa, LMX tidak memiliki pengaruh signifikan terhadap kinerja karyawan melalui kepuasan kerja, yang berarti uji mediasi sobel test ditolak.

\section{Pengaruh Leader Member Exchange (LMX) terhadap Kepuasan Kerja.}

Dari hasil pengujian, dapat diketahui bahwa LMX berpengaruh signifikan positif terhadap kepuasan kerja PT. Belian Jasa Terminal Indonesia. Penerapan LMX yang dirasakan karyawan PT Berlian Jasa 
Nuril Fitriana Indana Zulfa. Pengaruh $L M X$ terhadap Kinerja Karyawan melalui Kepuasan Kerja pada PT. Berlian Jasa Terminal Indonesia.

Terminal Indonesia cukup baik dan maksimal hal tersebut berdasarkan wawancara narasumber dengan karyawan staf mengatakan bahwa, hubungan lingkungan kerja yang ada di dalam BJTI antara atasan dan bawahan memang terjalin cukup harmonis, terdapat hubungan saling percaya yang diberikan atasan terhadap bawahannya. Hubungan saling percaya tersebut berupa tanggungjawap pekerjaan yang diberikan atasan terhadap bawahannya. Menurut wawancara dengan Bapak Puwoko selaku karyawan staf beliau mengatakan puas dengan tanggung jawap pekerjaan yang diberikan padanya sehingga beliau merasa bahwa benar-benar dilibatkan dalam pekerjaannya. Hal tersebut menimbulkan rasa percaya diri karyawan dalam mengembangkan kemampuannya.

Hasil penelitian ini memerkuat penelitian Anggreani \& Sutanto (2013), Eşitti \& Kasap (2019) serta Pramastuti \& Widodo (2015) yang menyatakan bahwa hubungan LMX yang berkualitas tinggi mengakibatkan kepuasan kerja akan semakin meningkat. Dengan demikian semakin tinggi kualitas LMX dalam organisasi, maka akan meningkatkan kepuasan kerja pada PT Berlian Jasa Terminal Indonesia.

\section{Pengaruh Kepuasan Kerja terhadap Kinerja Karyawan}

Dari hasil pengujian diketahui bahwa kepuasan kerja berpengaruh signifikan positif terhadap kinerja karyawan PT. Belian Jasa Terminal Indonesia. Dukungan PT Berlian Jasa Terminal Indonesia kepada karyawan dinilai cukup baik, sehingga membuat karyawan merasa puas dan terpacu untuk meningkatkan kinerja lebih baik lagi. Hal tersebut didukung dengan wawancara dengan karyawan PT. Berlian Jasa Terminal Indonesia mengatakan bahwa beberapa karyawan menyatakan puas dengan pekerjaan yang dijalaninya saat ini, mereka merasa menikmati pekerjaannya karena pekerjaan tersebut sesuai dengan apa yang diinginkannya dan sesuai dengan keahlian yang dimilikinya, maka dari itu mereka juga akan melakukan pekerjaannya dengan baik dan semaksimal mungkin.

Menurut wawancara tidak terstruktur, staf karyawan mengatakan bahwa kesempatan promosi di PT. Berlian Jasa Terminal Indonesia cukup banyak, diantaranya sistem Penilaian Individu (PI) dan sistem penilaian Sasaran Kinerja Induvidu (SKI). Sistem tersebut digunakan untuk mengetahui standrard kinerja pada karyawan yang nantinya pada karyawan yang memiliki penilaian tinggi dan terus meningkat akan diberikan bonus, reward dan jenjang karir. Berdasarkan hasil wawancara tidak terstruktur dengan Ibu Yenny selaku staf pengembangan organisasi human capital beliau mengatakan bahwa gaji yang diterima selama ini sudah cukup untuk memenuhi kebutuhan. Uang lembur yang diberikan PT. Berlian Jasa Terminal Indonesia cukup besar yaitu dengan kisaran 2 kali lipat dari gaji pokok perharinya.

Hasil penelitian ini mendukung penelitian Kristine (2017), Maharani et al. (2013) serta Febriyana (2015), bahwa kepuasan kerja berpengaruh signifikan positif terhadap kinerja karyawan. Sehingga semakin besar kepuasan kerja sebuah organisasi akan meningkatkan kinerja karyawan pada PT. Berlian Jasa Terminal Indonesia.

\section{Pengaruh LMX terhadap Kinerja Karyawan}

Hasil pengujian menunjukkan bahwa, tidak terdapat pengaruh signifikan antara kepuasan kerja terhadap kinerja karyawan PT. Berlian Jasa Terminal Indonesia. Artinya, tinggi rendahnya pengaruh LMX yang dirasakan karyawan belum bisa memengaruhi kinerja karyawan pada PT Berlian Jasa Terminal Indonesia. Hasil penelitian selaras dengan Kartika \& Suharnomo (2016), Joo (2012) serta Pusparini (2018) yang mengatakan bahwa LMX tidak berpengaruh terhadap kinerja karyawan. Berdasarkan hasil wawancara tidak terstruktur dengan Ibu Fenny selaku staf pengembangan Human Capital, mengatakan bahwa karyawan dituntut sigap dan tepat waktu dalam penyelesaian pekerjaannya. Hasilnya terbukti karyawan selalu bisa mengerjakan pekerjaan sesuai target yang ditetapkan perusahaan.

Menurut wawancara yang dilakukan dengan narasumber Bapak Rinaldo, beliau mengatakan bahwa produksi dari kinerja karyawan yang maksimal tidak sepenuhnya diperoleh dari hubungan baik antara atasan dan bawahan. Hal tersebut dikarenakan penilaian kinerja pada PT Berlian Jasa Terminal Indonesia sudah terstruktur oleh perusahaan seperti adanya pemenuhan target, contohnya operator 
HMC (Harbour Mobile Crane) yang bisa mencapai 2.500 box petikemas per bulan. Sehingga untuk mendapatkan kinerja yang maksimal dalam melakukan pemenuhan target tersebut tidak membutuhkan hubungan yang baik dengan atasannya.

Hasil wawancara dengan Bapak Sapta selaku karyawan operasional mengatakan bahwa hubungan antara karyawan dengan atasan tidak terlalu dekat. Hal tersebut dikarenakan atasan mempunyai kesibukan sendiri mengenai tugas dan tanggungjawabnya selaku atasan. Sehingga mengakibatkan hubungan beliau tidak terjalin dekat. Namun hal itu tidak membuat kinerja bapak sapta menurun karena bagi beliau target perusahaan cepat tercapai apabila bekerja sesuai dengan SOP (Standard Operating Procedure) yang berlaku di perusahaan. Dari hasil tersebut, LMX bukan menjadi faktor tinggi rendahnya kinerja karyawan PT. Berlian Jasa Terminal Indonesia.

\section{Pengaruh Leader Member Exchange (LMX) terhadap Kinerja Karyawan melalui Kepuasan Kerja}

Hasil penelitian ini diketahui bahwa tidak ada peran mediasi antara LMX terhadap kinerja karyawan. Hasil wawancara dengan Ibu Mega selaku supervisor pengembangan dan pelatihan divisi human capital, mengatakan bahwa hubungan atasan dan bawahan cukup dekat seperti hubungan pertemanan dikarenakan sering terjadinya interaksi antara atasan dan bawahan terkait hubungan pekerjaan. Namun dengan adanya variabel kepuasan kerja sebagai variabel mediasi itu tidak terbukti, hal tersebut dikarenakan ada faktor lain yang dirasakan karyawan yang memengaruhi tingkat kepuasan kerja karyawan di PT. Berlian Jasa Terminal Indonesia. Berdasarkan pembahasan sebelumnya, faktor lain yang dapat memengaruhi tinggi rendahnya kepuasan kerja karyawan yaitu beban kerja dan stres kerja, karena berdasarkan hasil wawancara pada karyawan PT Berlian Jasa Terminal Indonesia yang menyatakan intensitas pekerjaan yang dilakukan dirasa cukup berat, pekerjaan yang dilakukannya cukup menguras tenaga dan pikiran yang mengindikasikan bahwasanya beban kerja yang dirasakannya cukup tinggi, Ibu Lilis mengatakan bahwa aturan lembur pada PT Berlian Jasa Terminal Indonesia yaitu maksimal 60 jam/bulan. Namun masih ada karyawan yang lembur di atas ketentuan yang berlaku pada perusahaan.

Hal tersebut dilakukan, guna bisa memenuhi target yang sudah ditetapkan oleh perusahaan. Pernyataan itu sesuai dengan penelitian dilakukan oleh Wijaya (2018) dan paramita \& Subudi (2017) bahwa tinggi rendahnya beban kerja cenderung akan berdampak pada kepuasan kerja karyawan. Jadi, kepuasan kerja tidak mampu memediasi hubungan antara LMX terhadap kinerja karyawan pada PT. Berlian Jasa Terminal Indonesia.

\section{KESIMPULAN}

Kesimpulan yang dapat diambil dalam penelitian ini yaitu LMX berpengaruh secara signifikan terhadap kepuasan kerja pada PT. Berlian Jasa Terminal Indonesia, hal terbut dikarenakan terdapat hubungan harmonis antara atasan dan bawahan serta memiliki hubungan saling percaya. Kepuasan kerja memiliki pengaruh signifikan positif terhadap kinerja karyawan PT. Berlian Jasa Terminal Indonesia. LMX tidak memiliki pengaruh terhadap kinerja karyawan pada PT. Berlian Jasa Terminal Indonesia, hal tersebut dikarenakan penilaian kinerja sudah terstruktur oleh perusahaan sehingga untuk mendapatkan kinerja yang maksimal tidak membutuhkan hubungan yang baik dengan atasan. Variabel intervening kepuasan kerja belum mampu memengaruhi hubungan antara LMX dengan kinerja karyawan PT. Berlian Jasa Terminal Indonesia hal ini dikarenakan beban kerja dirasa karyawan cukup tinggi.

Indikator dari variabel LMX yaitu trust (kepercayaan), respect (kepedulian), dan obligation (kewajiban) dalam penelitian ini masuk dalam kategori sedang, sebaiknya perlu adanya pendekatan antara atasan dan bawahan dengan meningkatkan komunikasi dan interaksi. Sebagai upaya meningkatkan kepuasan kerja perlu adanya fasilitas tambahan seperti tempat istirahat bagi karyawan. Sebagai upaya mempertahankan kinerja karyawan, perusahaan dapat memberikan pelatihan-pelatihan berkala untuk menghadapi tuntutan dan tantangan dalam pekerjaan di masa depan. 
Nuril Fitriana Indana Zulfa. Pengaruh $L M X$ terhadap Kinerja Karyawan melalui Kepuasan Kerja pada PT. Berlian Jasa Terminal Indonesia.

Pada penelitian ini hasil perhitungan dari tiga variabel menunjukkan ketetapan model sebesar 16,4\% untuk sisanya 83,6\% dijelaskan oleh variabel lain. Diperkuat oleh hasil wawancara di lapangan, bahwa terdapat intensitas beban kerja dan stres kerja yang cukup tinggi. Karena itu, pada penelitian selanjutnya agar menambahkan variabel lain seperti beban kerja dan stres kerja, yang diharapkan dapat menjelaskan kinerja karyawan yang lebih signifikan.

\section{DAFTAR PUSTAKA}

Adi, S. T., Aju, B. I., \& Ayu, B. I. (2018). Effect of Competence, Leader-Member Exchange and Teamwork on Work Discipline, Job Stress and Their Impact on Employee Performance of Construction Company in East Java, Indonesia. RJOAS, 30(February), 108-114. https://doi.org/10.6018/analesps.33.3.238551

Ali, M., Idris, A., \& Kalalinggi, R. (2013). Pengaruh Kepuasan Kerja Terhadap Kinerja Pegawai pada Badan Ketahanan Pangan dan Pelaksana Penyuluhan Daerah Kota Samarinda. EJournal Administrative Reform, 1(2), 418-430.

Anggreani, W. E., \& Sutanto, E. M. (2013). Pengaruh Leader Member Exchange Terhadap Kepuasan Kerja , Motivasi Kerja Dan Komitmen Organisasional Karywan Departemen Penjualan Pada PT . X. AGORA, l(1).

Bhatti, G. A., Islam, T., Mirza, H. H., \& Ali, F. H. (2015). The Relationships Between LMX , Job Satisfaction and Turnover Intention. Science International, 27(2), 1523-1526.

Duyan, M., \& Y1ldı, S. M. (2018). The Effect of Leader-Member Exchange on Job Performance of Academic Staff: An Empirical Evidence from Higher Education Institutions. Journal of Human Sciences, 15(2), 1129-1136. https://doi.org/10.14687/jhs.v15i2.5162

Eşitti, B., \& Kasap, M. (2019). The Impact of Leader-Member Exchange on Lodging Employees' Dynamic Capacities: The Mediating Role of Job Satisfaction. Tourism and Hospitality Research, 1(8). https://doi.org/10.1177/1467358419826397

Febriyana, W. (2015). Pengaruh Kepuasan Kerja Terhadap Kinerja Karyawan PT . Kabepe Chakra. EProceeding of Management, 2(3), 2954-2961.

Ghozali, I. (2018). Aplikasi Analisis Multivariate dengan Program IBM SPSS 25. (9th ed.). Semarang: Badan Penerbit Universitas Diponegoro.

Handoko, T. H. (2014). Manajemen personalia dan sumber daya manusia (2nd ed.). Yogyakarta: BPFE.

Hasibuan, M. S. P. . (2017). Manajemen Sumber Daya Manusia (14th ed.). jakarta: Bumi Aksara.

Husain, U. (2008). Metode Penelitian Untuk Skripsi dan Tesis Bisnis (2nd ed.). Jakarta: PT Rajagrafindo Persada.

Hutama, P., \& Goenawan, R. (2017). Pengaruh Leader Member Exchange terhadap Kinerja Karyawan di Hotel X Surabaya. Jurnal Hospitality dan Manajemen Jasa, 05(2), 522-533.

Inuwa, M. (2016). Job Satisfaction and Employee Performance: An Empirical Approach. The Millennium University Journal, $1(1), \quad 90-103$. https://doi.org/10.1161/STROKEAHA.112.655050

Iroegbu, M. (2013). Effect of Organizational Role Conflict and Job Satisfaction on Performance in the Nigerian Customs Service: An Empirical Examination. International Journal of Applied 
Psychology, 3(6), 174-181. https://doi.org/10.5923/j.ijap.20130306.05

Joo, B. K. (2012). Leader-Member Exchange Quality and In-Role Job Performance: The Moderating Role of Learning Organization Culture. Journal of Leadership and Organizational Studies, 19(1), 25-34. https://doi.org/10.1177/1548051811422233

Kartika, D., \& Suharnomo. (2016). Pengaruh Pertukaran Pemimpin-Anggota (LMX) Terhadap Kinerja Karyawan Dengan Kepuasan Kerja Dan Keterlibatan Karyawan Sebagai Variabel Mediasi (Studi Pada Hotel Bahari Inn Tegal), 5(2), 1-14.

Kong, F., Huang, Y., Liu, P., \& Zhao, X. (2016). Why Voice Behavior? An Integrative Model Of The Need For Affiliation, The Quality Of Leader - Member Exchange , And Group Cohesion In Predicting Voice Behavior. Group \& Organization Management, (288), 1-27. https://doi.org/10.1177/1059601116642084

Kristine, E. (2017). Pengaruh Kepuasan Kerja dan Komitmen Organisasi Terhadap Kinerja Melalui Motivasi Kerja Pegawai Alih Daya (Outsourcing) Di PT. Mitra Karya Jaya Sentosa, 14(2), 384401.

Liao, S. S., Hu, D. C., Chung, Y. C., \& Chen, L. W. (2017). LMX and employee satisfaction: mediating effect of psychological capital. Leadership and Organization Development Journal, 38(3), 433-449. https://doi.org/10.1108/LODJ-12-2015-0275

Lie, T. F., \& Siagian, H. (2018). Pengaruh Kepuasan Kerja Terhadap Kinerja Karyawan Melalui Motivasi Kerja Pada CV. Union Event Planner, 6(1), 1-6.

Maharani, V., Troena, E. A., \& Noermijati. (2013). Organizational Citizenship Behavior Role In Mediating The Effect Of Transformational Leadership, Job Satisfaction On Employee Performance: Studies In PT Bank Syariah Mandiri Malang East Java. International Journal of Business and Management, 8(17), 1-12. https://doi.org/10.5539/ijbm.v8n17p1

Mangkunegara, A. P. (2017). Manajemen Sumber Daya Manusia Perusahaan (14th ed.). Bandung: Rosda.

Miner, J. B. (1998). Organizational Behaviour, Performance and Productivity (1st ed.). USA: Random House Inc.

Nurhaidah, \& Musa, M. I. (2015). pembaharuan dalam pemanfaatan hasil-hasil teknologi. Jurnal Pesona Dasar, 3(3), 1-14.

Paramita, M. M., \& Made, S. (2017). Turnover Intention Melalui Mediasi Kepuasan Kerja Pada Hoki Bank Cabang Gatot Subroto. E-Jurnal Manajemen Unud, 6(12), 6441-6470.

Pramastuti, Y. I., \& Widodo, P. B. (2015). Leader Member Exchange (LMX) dan Kepuasan Kerja pada Keryawan Bagian Produksi PT. Dua Kelinci Pati. Jurnal Empati, 4(4), 245-249.

Pusparini, A. ceisa. (2018). Pengaruh Leader Member Exchange Dan Empowerment Terhadap Kinerja Karyawan Melalui Kepuasan Kerja. Jurnal Ilmu Manajemen, 4(2), 38-50.

Sari, R. N. I., \& Hadijah, H. S. (2016). Peningkatan Kinerja Pegawai Melalui Kepuasan Kerja Dan Disiplin Kerja. Jurnal Pendidikan Manajemen Perkantoran, 1(1), 204-214.

Sari, R. P., \& Tiarapuspa. (2017). Hubungan Leader Member Exchane Dan Turnover Intention Yang Dimediasi Oleh Organization Identification. Jurnal Manajemen Bisnis, 12(2), 175-186. 
Nuril Fitriana Indana Zulfa. Pengaruh $L M X$ terhadap Kinerja Karyawan melalui Kepuasan Kerja pada PT. Berlian Jasa Terminal Indonesia.

Shu, C.-Y., \& Lazatkhan, J. (2017). Effect of leader Member Exchange on Employee Envy and Work Behavior Moderated by Self Steem and Neuroticism. Revista de Psicologia Del Trabajo y de Las Organizaciones, 33(1), 69-81. https://doi.org/10.1016/j.rpto.2016.12.002

Siswanto. (2015). Pengantar Manajemen (11th ed.). Jakarta: Bumi Aksara.

Susanto, N. (2019). Pengaruh Motivasi Kerja, Kepuasan Kerja, Dan Disiplin Kerja Terhadap Kinerja Karyawan Pada Divisi Penjualan PT Rebeka. Agora, 7(1), 1-7.

Taqiuddin, H., Tricahyadinata, I., \& Sampeliling, A. (2018). Pengaruh Leader Member Exchange dan Komitmen Organisasi terhadap Kinerja Karyawan Teladan Prima Group Kota Samarind. Forum Ekonomi, 20(2), 111-122.

Wibowo. (2014). Manajemen Kinerja (4th ed.). Jakarta: Rajawali Pers.

Wijaya, I. K. (2018). Pengaruh Kepuasan Kerja Terhadap Kinerja Karyawan CV Bukit Sanomas. AGORA, 6(2), 1-5.

Wojtczuk-turek, A. (2013). Innovativeness in Organizations: The Role of LMX and Organizational Justice. The Case of Poland. International Journal of Synergy and Research, 2(1), 41-55. 